\title{
Neuropsychiatric symptoms as the main determinant of caregiver burden in Alzheimer's disease
}

\author{
Renata Kochhann ${ }^{1,2}$,Ericksen Borba ${ }^{1,2}$, Maria Otília Cerveira ${ }^{1}$, Diego Onyszko ${ }^{1}$, \\ Alyne de Jesus ${ }^{1}$, Letícia Forster ${ }^{1}$, Luisa Franciscatto ${ }^{1}$, Cláudia Godinho ${ }^{1,2}$, \\ Ana Luiza Camozzato ${ }^{1,2,3}$, Márcia Lorena F. Chaves ${ }^{1,2,4}$
}

\begin{abstract}
Caregiver burden is common in Alzheimer's disease (AD), decreasing the quality of life among caregivers and patients. Projections of aging and aging-related diseases such as AD in developing countries justify additional data about this issue because people living in these countries have shown similarly high levels of caregiver strain as in the developed world. Objective: The aim of this study was to analyze the association of AD caregivers' burden with patients' neuropsychiatric symptoms (NPS), cognitive status, severity of dementia, functional capacity, caregiver sociodemographic characteristics, and the characteristics of care provided by caregivers. Methods: A cross-sectional study was conducted in a sample of 39 consecutive AD patients and their primary caregivers. NPS were evaluated using the Neuropsychiatric Inventory (NPI). Severity of dementia was assessed with the Clinical Dementia Rating (CDR) scale. Functional capacity was assessed using the Katz and Lawton scales. The burden level was rated using the Burden Interview (BI). Sociodemographic characteristics of caregivers and the characteristics of care provided by them were evaluated. The Mann-Whitney U-test, KruskalWallis test and Spearman's rho coefficient were performed. Results: The BI had a moderate correlation with NPI intensity (rho=0.563), $\mathrm{p}<001$. Female caregivers reported a greater level of burden $(\mathrm{p}=0.031)$ than male caregivers. The other variables were not significantly associated to caregiver burden. Conclusion: NPS were the main determinant of burden in primary caregivers of $\mathrm{AD}$ patients. This result underscores the need for prevention and treatment of these symptoms. Sex also had an effect on caregiver burden, but the small male sample in this study precludes the generalization of this finding.
\end{abstract}

Key words: neuropsychiatric symptoms, caregiver burden, Alzheimer's disease patients.

\begin{abstract}
Sintomas neuropsiquiátricos como o principal determinante da sobrecarga do cuidador na doença de Alzheimer Resumo - Sobrecarga no cuidador é comum na doença de Alzheimer (DA), diminuindo a qualidade de vida dos cuidadores e pacientes. As projeções de envelhecimento e doenças relacionadas ao envelhecimento como a DA nos países em desenvolvimento justificam dados adicionais sobre esta questão, porque as pessoas que vivem nestes países têm apresentado níveis semelhantes de sobrecarga no cuidador tão alto quanto no mundo desenvolvido. Objetivo: $\mathrm{O}$ estudo teve como objetivo analisar a associação da sobrecarga em cuidadores de pacientes com DA com sintomas neuropsiquiátricos (NPS) dos pacientes, estatus cognitivo, gravidade da demência, capacidade funcional, características sociodemográficas do cuidador e as características dos cuidados prestados pelos cuidadores. Métodos: Um estudo transversal foi realizado em uma amostra de 39 pacientes consecutivos de DA e seus cuidadores primários. NPS foram avaliados através do Inventário Neuropsiquiátrico (NPI). A gravidade da demência foi avaliada com a escala Clinical Dementia Rating (CDR). A capacidade funcional foi avaliada com as escalas de Katz e Lawton. O nível de sobrecarga foi avaliada utilizando a escala Burden Interview (BI). Características sociodemográficas dos cuidadores e as características de atendimento prestado por eles foram
\end{abstract}

${ }^{1}$ Dementia Clinic, Neurology Service, Hospital de Clínicas de Porto Alegre, Porto Alegre RS, Brazil; ${ }^{2}$ Medical Sciences Post-Graduation Course, UFRGS School of Medicine, Porto Alegre RS, Brazil; ${ }^{3}$ Internal Medicine Department and Health Sciences Post-Graduation Course, UFCSPA School of Medicine, Porto Alegre RS, Brazil; ${ }^{4}$ Internal Medicine Department, UFRGS School of Medicine, Porto Alegre RS, Brazil.

Márcia L.F. Chaves - Rua Ramiro Barcelos, 2350 / sala 2040 - 90035-091 Porto Alegre - Brazil. E-mail: mchaves@hcpa.ufrgs.br

Disclosure: The authors reports no conflicts of interest.

Received April 29, 2011. Accepted in final form July 04, 2011. 
avaliadas. Mann-Whitney, Kruskal-Wallis e coeficiente rho de Spearman foram calculados. Resultados: BI apresentou correlação moderada com a intensidade do NPI (rho=0,563), $\mathrm{p}<001$. Cuidadoras mulheres relataram maior nível de sobrecarga $(\mathrm{p}=0,031)$ do que cuidadores do sexo masculino. As demais variáveis não foram significativamente associados à sobrecarga do cuidador. Conclusão: NPS foram o principal determinante da sobrecarga do cuidador de pacientes com DA. Esse resultado reforça a necessidade de prevenção e tratamento desses sintomas. Sexo também teve um efeito sobre a sobrecarga do cuidador, mas a pequena amostra do sexo masculino neste estudo evita a generalização dessa constatação.

Palavras-chave: sintomas neuropsiquiátricos, sobrecarga do cuidador, pacientes com doença de Alzheimer.

Alzheimer's disease (AD) is stressful for those who acquire it, and also for the caregivers of these patients. Some characteristics have been studied to determine caregiver burden including severity of the dementia, behavioral problems and patient's activities of daily living; age of caregiver, problem-solving ability and perception of disease by caregivers; financial resources, social support, cognitive and functional impairment of patients. ${ }^{1}$

Studies on the care arrangements for people with dementia living in developing countries have shown that levels of caregiver strain were at least as high as in the developed world. ${ }^{2}$ Therefore, the projections of aging and aging-related diseases such as $\mathrm{AD}$ in these regions justify the search for additional data about this issue.

In a previous evaluation by our group, no relationship was found between caregiver demographic variables and caregiver distress (evaluated with the Neuropsychiatric Inventory-Distress scale - NPI-D). ${ }^{3}$

As NPI-D analyzes distress related to specific neuropsychiatric symptoms it was decided to evaluate burden in general (using the Zarit Burden Interview - BI) and to analyze the association between caregiver demographic characteristics and BI. However, we first hypothesized that caregivers from developing countries taking care of patients under the public health system, albeit in a university hospital, would be from lower social classes and exhibit higher levels of burden. We also hypothesized that the following characteristics would be associated with higher levels of burden: being in charge of patients with severe dementia; being a full time caregiver; and having lower educational attainment. Therefore, the aim of the study was to analyze the association of AD caregivers' burden with patients' neuropsychiatric symptoms, cognitive status, severity of dementia, functional capacity, caregiver sociodemographic characteristics, and the characteristics of care provided by caregivers.

\section{Methods}

A cross-sectional study was conducted in a sample of 39 consecutive patients and their primary caregivers.
Participants were enrolled from the Dementia Clinic of Hospital de Clinicas de Porto Alegre (a public university hospital) after giving informed consent. Primary caregiver was defined as someone who spent at least $20 \mathrm{~h}$ per week giving care. All patients fulfilled the DSM-IV criteria for dementia, ${ }^{4}$ and the NINCDS-ADRDA criteria for probable Alzheimer's disease. ${ }^{5}$

For assessment of cognitive status, all patients underwent evaluation with the Mini Mental State Examination (MMSE) ${ }^{6-8}$ Functional capacity was evaluated with the Katz and Lawton scales. ${ }^{9}, 10$

The severity of dementia was assessed using the Clinical Dementia Rating (CDR) scale. ${ }^{11-13}$ The CDR evaluates memory, orientation, judgment and problem solving, community affairs, home and hobbies, and personal care. This instrument allows the clinicians to categorize patient disease into mild $(\mathrm{CDR}=1)$, moderate $(\mathrm{CDR}=2)$ or severe $(\mathrm{CDR}=3)$ dementia.

Neuropsychiatric symptoms were evaluated using the Neuropsychiatric Inventory (NPI). ${ }^{14,15}$ The NPI consists of three sections for each symptom: frequency, severity, and distress. The information was obtained from the caregiver who had observed the symptoms in the patient during a specific period. Each caregiver was asked an initial screening question for each of the 12 neuropsychiatric domains. If the screening question was negatively answered, the interviewer moved on to the next domain. If it was positively answered, further questions were asked, allowing scores for both severity (range: 1 [mild] -3 [marked]) and frequency (range: 1 [occasional] -4 [very frequent]) of each symptom. An intensity score was then obtained by multiplying the scores of severity by frequency (range: $0-12$ for each item).

Burden was rated with the Burden Interview (BI). ${ }^{16-18}$ BI consists of a 22 -item questionnaire which verifies the burden perceived by the caregivers concerning: request for help from patients, lack of personal time, feeling of tiredness, embarrassment, irritation, tension, lack of privacy, feeling that the caregiver's social life is impaired, among others. Questions from 1 to 21 are answered by assigning the following levels of frequency: never $=0$, rarely $=1$, some- 
times $=2$, quite frequently $=3$, or nearly always $=4$. Question 22 assesses, in general terms, the burden felt by the caregiver and can be scored using the following alternatives: not at all $=0$, a little $=1$, moderately $=2$, quite a $b i t=3$, extreme$l y=4$. Total scores range from 0 to 88 , and the higher the score, the higher the level of burden.

Caregivers' demographic data and care characteristics (i.e., relationship with the patient - spouse, daughter/son, other relative, non relative -, self-reported number of hours per week spent giving care, time as caregiver, whether the caregiver lives with patient and whether the caregiver receives payment for care) were evaluated. Caregiver social class was also evaluated with a Brazilian scale which allows classification into A, B, C, D or E classes, where A is the highest level. ${ }^{19}$

\section{Statistical analyses}

Descriptive statistics (mean, SD and frequency) were calculated for demographic data, NPI scores of intensity, MMSE scores and BI total score. The Mann-Whitney Utest, Kruskal-Wallis test and Spearman's rho coefficient were performed. The statistical analysis was performed using the Statistical Package for the Social Sciences (SPSS 18.0 for Windows).

\section{Results}

Demographic and clinical data from patients and caregivers are shown in Table 1.

BI presented moderate correlation with NPI intensity $(\mathrm{rho}=0.563), \mathrm{p}<001$. We also found similar distribution of

Table 1. Clinical and demographic data of patients and caregivers.

\begin{tabular}{|c|c|c|}
\hline Variables & $\mathrm{AD}$ patients & Caregivers \\
\hline \multicolumn{3}{|l|}{ Sex N (\%) } \\
\hline Female & $26(67)$ & $31(80)$ \\
\hline Male & $13(33)$ & $8(20)$ \\
\hline \multicolumn{3}{|l|}{ CDR N (\%) } \\
\hline 1 & $13(33)$ & - \\
\hline 2 & $13(33)$ & - \\
\hline 3 & $13(33)$ & - \\
\hline \multicolumn{3}{|l|}{ Relationship to patient } \\
\hline Spouse & - & $11(28)$ \\
\hline Daughter/son & - & $27(69)$ \\
\hline Other relative & - & $1(3)$ \\
\hline \multicolumn{3}{|l|}{ Social class N (\%) } \\
\hline$A$ and $B$ & - & $25(64)$ \\
\hline $\mathrm{C}, \mathrm{D}$ and $\mathrm{E}$ & - & $14(36)$ \\
\hline \multicolumn{3}{|l|}{ Full time job as caregiver $\mathrm{N}(\%)$} \\
\hline Yes & - & $29(74)$ \\
\hline No & - & $10(26)$ \\
\hline Caregiver lives with patient N (\%) & - & $33(85)$ \\
\hline Caregiver is unpaid for care of patient $\mathrm{N}(\%)$ & - & $38(97)$ \\
\hline Time as caregiver in months ${ }^{\star}$ (range) & - & $62.10 \pm 49.68(7-216)$ \\
\hline Caregiver hours per week ${ }^{\star}$ (range) & - & $100.69 \pm 23.38(25-112)$ \\
\hline Age $^{\star}$ (range) & $77.56 \pm 8.01(52-90)$ & $52.90 \pm 13.11(20-79)$ \\
\hline Years of education ${ }^{\star}$ (range) & $4.54 \pm 4.14(0-16)$ & $10.08 \pm 4.79(2-22)$ \\
\hline $\mathrm{MMSE}^{\star}$ (range) & $10.54 \pm 6.58(0-24)$ & - \\
\hline NPI Intensity (range) & $33.51 \pm 22.56(0-82)$ & - \\
\hline $\mathrm{ADL}^{\star}$ (range) & $8.13 \pm 6.14(0-18)$ & - \\
\hline $\mathrm{IADL}^{\star}$ (range) & $10.82 \pm 3.42(3-14)$ & - \\
\hline $\mathrm{BI}^{*}$ (range) & - & $33.51 \pm 15.75(3-68)$ \\
\hline
\end{tabular}


Table 2. Analyses of BI scores on categorical variables.

\begin{tabular}{|c|c|c|}
\hline Variables & $\mathrm{BI}$ mean \pm SD & p value \\
\hline \multicolumn{3}{|l|}{ Caregiver's sex ${ }^{*}$} \\
\hline Female & $36.19 \pm 16.11$ & \\
\hline Male & $23.13 \pm 8.93$ & 0.031 \\
\hline \multicolumn{3}{|c|}{ Caregiver lives with patient ${ }^{\star}$} \\
\hline Yes & $35.33 \pm 15.48$ & \\
\hline No & $23.50 \pm 14.48$ & 0.106 \\
\hline \multicolumn{3}{|c|}{ Full time job as caregiver ${ }^{\star}$} \\
\hline Yes & $34.28 \pm 15.82$ & \\
\hline No & $31.30 \pm 16.17$ & 0.809 \\
\hline \multicolumn{3}{|l|}{$\mathrm{CDR}^{\star *}$} \\
\hline 1 & $33.08 \pm 19.64$ & \\
\hline 2 & $33.85 \pm 11.67$ & \\
\hline 3 & $34.62 \pm 16.13$ & 0.796 \\
\hline \multicolumn{3}{|c|}{ Relationship to patient ${ }^{* *}$} \\
\hline Spouse & $31.73 \pm 19.59$ & \\
\hline Daughter/son & $34.59 \pm 14.45$ & \\
\hline Other relative & 24.00 & 0.618 \\
\hline \multicolumn{3}{|l|}{ Social class* } \\
\hline$A$ and $B$ & $31.92 \pm 13.88$ & \\
\hline $\mathrm{C}, \mathrm{D}$ and $\mathrm{E}$ & $36.36 \pm 18.86$ & 0.379 \\
\hline \multicolumn{3}{|c|}{ Caregiver's type of care ${ }^{*}$} \\
\hline Paid & 47.00 & \\
\hline Unpaid & $33.16 \pm 15.80$ & 0.286 \\
\hline
\end{tabular}

NPS intensity among the different stages of dementia (severity) (Kruskal-Wallis U-test) $(\mathrm{p}=0.132)$. Other patient and caregiver variables showed no correlation with BI (i.e., age, education, time as caregiver, hours of care per week).

The data for comparison of the BI scores according to category (i.e., sex, dementia severity, social class) is given in Table 2. Female caregivers had higher levels of burden ( $p=0.031$ ) than male caregivers. No other categorical variable presented a statistically significant effect on caregiver BI scores.

\section{Discussion}

This study evaluated the association of burden of AD caregivers with patients' neuropsychiatric symptoms, cognitive status, dementia severity, functional capacity, caregiver sociodemographic characteristics, and characteristics of care provided by caregivers.

The main finding was a positive correlation between burden scores and neuropsychiatric symptoms (NPS), suggesting that behavioral disturbances are a key-factor predis- posing caregivers to distress, life disruptions, other physical and mental suffering. Other studies have previously reported this finding. ${ }^{20-23}$ Low levels of informal social support, ${ }^{20}$ decreased patient quality of life, ${ }^{23}$ lower patient functional capability $^{23}$ and severity of cognitive decline ${ }^{21}$ were also associated with higher levels of burden in theses studies.

In a previous study by our group, ${ }^{3}$ a significant correlation between total severity NPI and distress NPI was observed, but none of the caregiver demographic data were shown to be associated with distress. Taken together, previous and current results showed NPS to be correlated to distress and burden, independent of any specific neuropsychiatric or general symptoms. In the first study, apathy was the symptom responsible for the highest distress level, followed by agitation and aggression. The most frequent symptoms were apathy and aberrant motor behavior. Patients' relatives also considered apathy as the most severe symptom, followed by depression and agitation. ${ }^{3}$

In the present study, neither cognitive status or dementia severity was associated to levels of burden, supporting the notion that cognition and intensity of disease are not determinants of burden. Other patient and caregiver variables also showed no relationship with burden. However, sex had an effect on caregiver burden, but the small size of the male sample $(\mathrm{N}=8,20 \%)$ prevents generalization of this finding.

Individuals from developing countries taking care of patients, users of the public health system, albeit a university hospital were from lower social classes and had higher levels of burden. Besides lower financial means, inaccessibility to other resources could render these individuals more prone to burden. However, the findings of the present study failed to confirm this relationship. More than half of the sample (64\%) pertained to upper classes according to the Brazilian classification, and the variability of burden was high. This Brazilian classification for social class may present a bias towards higher levels because it takes into account purchasing power together with educational attainment, but income is not adequately weighted. Despite being largely used this measure may introduce some degree of bias.

The characteristics of being in charge of patients with severe dementia, being a full time caregiver, and having lower educational attainment were also not associated with higher burden. The distribution of the Burden Interview scores among dementia severity classes of patients was similar as were levels of neuropsychiatric symptoms (NPS) evaluated with the NPI, suggesting caregiver burden and patient intensity of neuropsychiatric symptoms may be independent of stage of disease (severity).

The main objective of the study was to assess primary caregivers and therefore most of the individuals were 
fulltime carers since this reflects the most common profile in Brazil. ${ }^{21}$ The present study showed a similar caregiver profile to Moscoso's study. ${ }^{21}$

One limitation of this investigation, besides the small sample size, was the lack of medical and personal variables from the caregiver such as depression, anxiety, and management strategies that could influence the perception of burden. Nevertheless, the objective of the study was the analysis of sociodemographic data, care and dementiarelated characteristics.

As neuropsychiatric symptoms are common in dementia and affect virtually all patients at some point in the course of the illness, ${ }^{24,25}$ the prevention and treatment of these symptoms are needed. Concerns about the safety and efficacy of psychotropic medications have been raised. Despite these concerns, medications are often prescribed for neuropsychiatric symptoms. ${ }^{26-28}$ Specific types of caregiver and residential care staff education, behavior management therapies, and possibly cognitive stimulation, appear to offer long-term effectiveness for the management of dementia-associated neuropsychiatric symptoms. ${ }^{29}$

Acknowledgments - We wish to thank the CAPES research funding body for providing Renata Kochhann with a scholarship. We would also like to thank the CNPQ research funding body for providing Ericksen Borba and Alyne de Jesus with scholarships. Finally, we extend our thanks to the FAPERGS research funding body for providing Diego Onyszko with a scholarship.

\section{References}

1. Rymer S, Salloway S, Norton L, Malloy P, Correia S, Monast D. Impaired awareness, behavior disturbance, and caregiver burden in Alzheimer disease. Alzheimer Dis Assoc Disord 2002; 16:248-253.

2. Prince M, 10/66 Dementia Research Group. Care arrangements for people with dementia in developing countries. Int J Geriatr Psychiatry 2004;19:170-177.

3. Godinho C, Camozzato A, Kochhann R, Chaves ML. Association of caregiver demographic variables with neuropsychiatric symptoms in Alzheimer's disease patients for distress on the Neuropsychiatric Inventory (NPI). Dement Neuropsychol 2008;2:211-216.

4. American Psychiatric Association. Diagnostic and Statistical Manual of Mental Disorders: DSM-IV $4^{\text {th }}$ ed. Washington, DC: American Psychiatric Association; 1994.

5. McKhann G, Drachman D, Folstein M, Katzman R, Price D, Stadlan EM. Clinical diagnosis of Alzheimer's disease: report from the NINCDS-ADRDA Work Group under the auspices of Department of Health and Human Services Task Force on Alzheimer's Disease. Neurology 1984;34:939-944.
6. Folstein MR, Folstein SE, McHugh PR. "Mini-mental State:" a practical method for grading the cognitive state of patients for the clinician. J Psychiatr Res 1975;12:189-198.

7. Chaves ML, Izquierdo I. Validity of the Clinical Dementia Rating scale for the detection and staging of dementia in Brazilian patients. Acta Neurol Scand 1992; 85:378-382.

8. Brucki SMD, Nitrini R, Caramelli P, Bertolucci PHF, Okamoto IH. Sugestões para o uso do Mini-Exame do Estado Mental no Brasil. Arq Neuropsiquiatr 2003;61:777-781.

9. Katz S, Ford AB, Moskowitz RW, Jackson BA, Jaffe MW. Studies of illness in the aged. The index of ADL: a standardized measure of biological and psychosocial function. JAMA 1963;185:914-919.

10. Lawton MP, Brody EM. Assessment of older people: Selfmaintaining and instrumental activities of daily living. The Gerontologist 1969;9:179-186.

11. Hughes CP, Berg L, Danziger WL, Coben LA, Martin RL. A new clinical scale for the staging of dementia. Brt J Psychiatry 1982;140:566-572.

12. Morris JC. The Clinical Dementia Rating (CDR): current version and scoring rules. Neurology 1993;43:2412-2414.

13. Chaves ML, Camozzato AL, Godinho C, et al. Validity of the Clinical Dementia Rating scale for the detection and staging of dementia in Brazilian patients. Alzheimer Dis Assoc Disord 2007;21:210-217.

14. Cummings JL. The Neuropsychiatric Inventory: assessing psychopathology in dementia patients. Neurology 1997;48: S10-S16.

15. Camozzato AL, Kochhann R, Simeoni C, et al. Reliability of the Brazilian Portuguese version of the Neuropsychiatric Inventory (NPI) for patients with Alzheimer's disease and their caregivers. Int Psychogeriatr 2008;20:383-393.

16. Zarit SH, Orr NK, Zarit JM. The hidden victims of Alzheimer's disease: Families under stress. New York: New York University Press; 1985.

17. Scazufca M. Brazilian version of the burden interview scale for the assessment of burden of care in carers of people with mental illnesses. Rev Bras Psiquiatr 2002;24:12-17.

18. Taub A, Andreoli SB, Bertolucci PH. Dementia caregiver burden: reliability of the Brazilian version of the Zarit caregiver burden interview. Cad Saúde Pública 2004;20:372-376.

19. ABEP - Associação Brasileira de Empresas de Pesquisa - 2008 www.abep.org - Dados com base no Levantamento Sócio Econômico - 2005 - IBOPE.

20. Coen RF, Swanwick GR, O’Boyle CA, Coakley D. Behaviour disturbance and other predictors of carer burden in Alzheimer's disease. Int J Geriatr Psychiatry 1997;12:331-336.

21. Moscoso MA, Marques RCG, Ribeiz SRI, et al. Profile of caregivers of Alzheimer's disease patients attended at a reference center for cognitive disorders. Dement Neuropsychol 2007;1:412-417. 
22. Fialho PPA, Koenig AM, Santos EL, et al. Dementia caregiver burden in a Brazilian sample: association to neuropsychiatric symptoms. Dement Neuropsychol 2009; 3:132-135.

23. Mohamed S, Rosenheck R, Lyketsos CG, Schneider LS. Caregiver burden in Alzheimer disease: cross-sectional and longitudinal patient correlates. Am J Geriatr Psychiatry 2010;18:917-927.

24. Lyketsos CG, Lopez O, Jones B, Fitzpatrick AL, Breitner J, DeKosky S. Prevalence of neuropsychiatric symptoms in dementia and mild cognitive impairment: Results from the cardiovascular health study. JAMA 2002;288:1475-1483.

25. Sink KM, Covinsky KE, Newcomer R, Yaffe K. Ethnic differences in the prevalence and pattern of dementia-related behaviors. J Am Geriatr Soc 2004;52:1277-1283.

26. Lopez OL, Wisniewski SR, Becker JT, Boller F, DeKosky ST.
Psychiatric medication and abnormal behavior as predictors of progression in probable Alzheimer's disease. Arch Neurol 1999;56:1266-1272.

27. Smith DA, Beier MT. Association between risperidone treatment and cerebrovascular adverse events: examining the evidence and postulating hypotheses for an underlying mechanism. J Am Med Dir Assoc 2004;5:129-132.

28. Wooltorton E: Risperidone (Risperdal): increased rate of cerebrovascular event in dementia trials. Can Med Assoc 2002; 167:1269-1270.

29. Livingston G, Johnston K, Katona C, Paton J, Lyketsos CG. Systematic review of psychological approaches to the management of neuropsychiatric symptoms of dementia. Am J Psychiatry 2005;162:1996-2021. 